\title{
A longitudinal study on the significance of environmental and individual factors associated with the development of essential hypertension
}

\author{
FOLKE LINDGÄRDE, ${ }^{1}$ MARGARETA FURU, ${ }^{2}$ AND BENGT-OLOV LJUNG ${ }^{2}$ \\ From the Department of Medicine, ${ }^{1}$ University of Lund, Malmö General Hospital, Malmö; and Stockholm Institute \\ of Education, ${ }^{2}$ Department of Educational Research, Stockholm, Sweden
}

SUMMARY Altogether 379 men of the same age have been followed for more than 40 years, mainly as regards socioeconomic conditions during the first 10 years as well as cognitive ability measured at the ages of 10 and 20, education, income development, and psychosocial conditions in adulthood. At the age of 48 a health investigation was performed. In order to identify possible risk factors associated with the development of raised blood pressure 38 subjects with essential hypertension were compared with 155 men without any obvious mental or somatic diseases. No differences regarding socioeconomic conditions during childhood could be observed between the two groups. However, $\square$ there was a very strong difference between father's education and the son's cognitive ability in the group with hypertension. The low income development for the group with hypertension can probably be explained partly by the lower cognitive ability. In the total group there was a positive correlation $\frac{\mathbb{Q}}{\circ}$ between IQ at the age of 10 and income at the age of $43(r=0.42 ; p<0.001)$. The hypertensive men were psychosocially disadvantaged with respect to divorce rate and job dissatisfaction, and furthermore they reported low physical activity during leisure time. Hypertensive men were more obese and had inferior respiratory function. The observation that a lower cognitive ability seems to beo related to the development of hypertension is compatible with the observation that early mortality in this investigated group has a correlation of a low IQ with poor socioeconomic conditions in childhood.

Essential hypertension is closely associated with some other risk factors for ischaemic heart disease, such as obesity, glucose intolerance and plasma insulin, ${ }^{1}$ and is inversely related to physical fitness. ${ }^{2}$ Besides being an established risk factor for cardiovascular disease, hypertension is associated with non-cardiovascular disabilities, according to data from the Framingham study. ${ }^{3}$

There appear to be three families of psychosocial and behavioural risk factors that are associated with increased risk of hypertension: social disadvantage, ${ }^{4}$ sustained vigilance, ${ }^{5}$ and certain defences against stress. ${ }^{6}$ However, these factors have seldom been the sabject of large-scale prospective epidemiological studies, as have been the factors associated with ischaemic heart disease. Cross-sectional and retrospective studies may observe variables that are associated with the maintenance of hypertension or may be the result of hypertension. Therefore, if influences from socioeconomic factors and personality contribute to the initial development of hypertension they may no longer be discernible in long-standing cases.

It is only longitudinal studies of representative groups followed from childhood up to at least middle age that can fully delineate the nature of the complex relations and mechanisms between genetic predisposition, environmental stimuli, and sustained high blood pressure.

According to the theory of general susceptibility, individuals with essential hypertension may have a genetic predisposition that plays a role in the development of sustained high blood pressure and other diseases. The hypothesis underlying that model is that social and psychological stimuli can act as stressors that, in predisposed individuals, may lead to disease.

The aim of this study was to elucidate if socioeconomic and psychosocial conditions during the first 10 years, as well as cognitive ability measured 
at the age of 10 , are factors related to the development of raised blood pressure in middle-aged men.

As it is well known that differences in social classes may explain the incidence and prevalence of diseases, ${ }^{7}$ the first approach was to analyse if middle-aged men with hypertension belonged to the same social class during their childhood as men of the same age without obvious mental and somatic disability. As there is evidence that, even within homogenous social groups, disease and illness are not randomly distributed, the second step was to identify other social and behavioural factors during the life span that may be risk indicators for the development of high blood pressure.

Therefore, in this exploratory study of middle-aged men with essential hypertension, the men were compared with subjects without mental or somatic disability with respect to certain social and behavioural variables during a period of about 40 years.

\section{Materials and methods}

The study was made possible by using data both from the so-called Malmö Study, ${ }^{8-10}$ and from a health investigation at the Section of Preventive Medicine, Department of Medicine, Malmö General Hospital.

\section{POPULATION}

The population consists of the men in the Malmö Study. This study was started in 1938 as a study of intelligence and social environment. (Malmö is the third largest town in Sweden and is located in the southern part of the country.) The study included all pupils in the third grade of Malmö's elementary and private schools - a total of 1542 pupils, of whom 834 were boys. Most of the pupils were 10 years old in 1938. Since the age of 10 , the group has been followed up for a period of more than 40 years, mainly as regards education, professional careers, and income development.

\section{STUDY GROUP}

During 1976-78 the 492 men from the Malmö Study population who were still living in Malmö were invited to a health investigation. Of these $492 \mathrm{men}, 379(77 \%)$ accepted the invitation. The 379 men did not differ in health respects from 48-year-old men in Malmö, nor did they differ from the Malmö Study average in the variables studied. ${ }^{10}$

\section{THE HYPERTENSIVE GROUP}

On the basis of findings at the medical examination, 38 men were diagnosed as hypertensive $(n=35)$ or borderline cases $(n=3)$. The criteria for the diagnosis of hypertension were either that the individual was already undergoing medical treatment for hypertension at the time of the health examination or that blood pressure after 10 minutes' rest in the supine position was $\geqslant 160 / 105 \mathrm{mmHg}$ on two different measurement occasions. Borderline hypertension meets the criteria only for either systolic or diastolic pressure. The two hypertensive categories will be shown as one group and termed hypertensive $(n=38)$.

\section{HEALTHY GROUP}

From the remaining 341 health-examined men, a comparison group of "healthy" men was selected. The following criteria disqualify individuals from being classified as "healthy": The medical examination reveals actual disease; the subject earlier had an anamnesis of glucose intolerance or diabetes mellitus, clinical or borderline alcoholism, cardiovascular diseases, cancer, tuberculosis, asthma, goitre, repeated attacks of kidney stones, albuminuria, joint pain; had undergone operation for gastric ulcer; had been treated or hospitalised for nervous or mental trouble; takes sleeping pills more than three times weekly or has taken sleeping pills regularly for a fairly long time; has full or partial sickness benefit; has a life annuity.

By the use of these criteria it was possible to classify 155 individuals as "healthy".

\section{BIOMEDICAL EXAMINATIONS}

The health screening procedure has been reported elsewhere. ${ }^{11}$ All investigations were performed in the morning after an overnight fast. An oral glucose tolerance test was performed with $30 \mathrm{~g}$ glucose $/ \mathrm{m}^{2}$ body surface area, given as an aqueous solution $(10 \mathrm{~g} / 100 \mathrm{ml})$ and ingested within 5 minutes. Relative body weight was calculated according to the formula: actual weight/ideal weight for body height.

Systolic and diastolic blood pressure (BP) were measured in the supine position at 0 minute and after rest for exactly 10 minutes. A mercury manometer was used, and the disappearance of the Korotkoff sounds was taken as diastolic BP (phase V).

ANSWERS TO QUESTIONS ASKED AT THE HEALTH INVESTIGATION

The persons examined also answered over 200 questions. These have been grouped into the following areas: diabetes in the family, cardiovascular disease in the family, smoking habits, alcohol habits, physical activity at work and in free time, psychological and social conditions, working conditions, digestive organ troubles.

Response alternatives were "yes", "no", and "don't know". With some exceptions, the questions were formulated so that a "yes" meant that the individual had a disadvantage in the relevant variable. There was no internal non-response: during the health examination, a nurse checked that all questions were 
answered. The percentages of "yes" answers to each question were compared between hypertensive and "healthy" men.

SOCIAL AND BEHAVIOURAL FACTORS DURING LIFE SPAN Of the "Malmö data," only those variables have been chosen that were relevant on theoretical grounds. The starting point was that variables known to exhibit statistical connections with early death were chosen. ${ }^{12}$ These risk indicators are socioeconomic background, early cognitive ability, level of education, and socioeconomic status in adulthood.

\section{STATISTICAL ANALYSIS}

Profile analyses were performed for healthy and hypertensive subjects respectively. Differences between groups were tested using Student's $t$-test (two-tailed) and $\chi^{2}$ analyses.

\section{Results}

SOCIOECONOMIC AND BEHAVIOURAL FACTORS IN A LIFELONG PERSPECTIVE

Figure 1 shows standardised means for hypertensive compared with "healthy" men as to socioeconomic background, cognitive ability, and development of income in adulthood. In the standardisation, the mean in the total group $(n=379)$ has been set at 100 and the standard deviation at 50 for each variable.

The figure shows that there are no differences regarding family income during childhood between the two groups. However, another indicator of social class, father's education, shows that the hypertensive subjects in childhood belonged to families in which the father, on average, had been better educated than is the case for the "healthy" group $(p<0.01)$. It is noteworthy that family income does not differ in the same way. There is also a discrepancy between father's educational level and son's cognitive ability, which is relatively low $(p<0 \cdot 10)$. The IQ measures are, however, in accordance with the grade point averages. All those measures of cognitive ability are lower for the hypertensive subjects. The children's experiences of parent's expectations regarding future education are similar for the two groups. However, the cognitive ability was different, as mentioned, and may be the cause for the less favourable development of income in adulthood $(p<0 \cdot 10)$. The figure shows that the IQ measures for the two groups are stable over time. It can also be seen that among the hypertensive men the educational level at adulthood for the children is on average lower than their fathers' educational levels. No similar downward educational mobility is observed for the "healthy" group.

Concerning other social factors for 1938, the groups have been compared in the following respects: social $\vec{\mathbb{}}$ 을 welfare assistance to the family, family composition $\frac{?}{\mathbb{C}}$. expressed in family size ( $\geqslant 6$ persons), and whether $\propto$ only one adult is at home. No statistically significant $<\frac{\mathbb{D}}{0}$ differences between the hypertensive and "healthy" $\delta$ men were found in these respects.

As figure 2 indicates, the hypertensive differ from

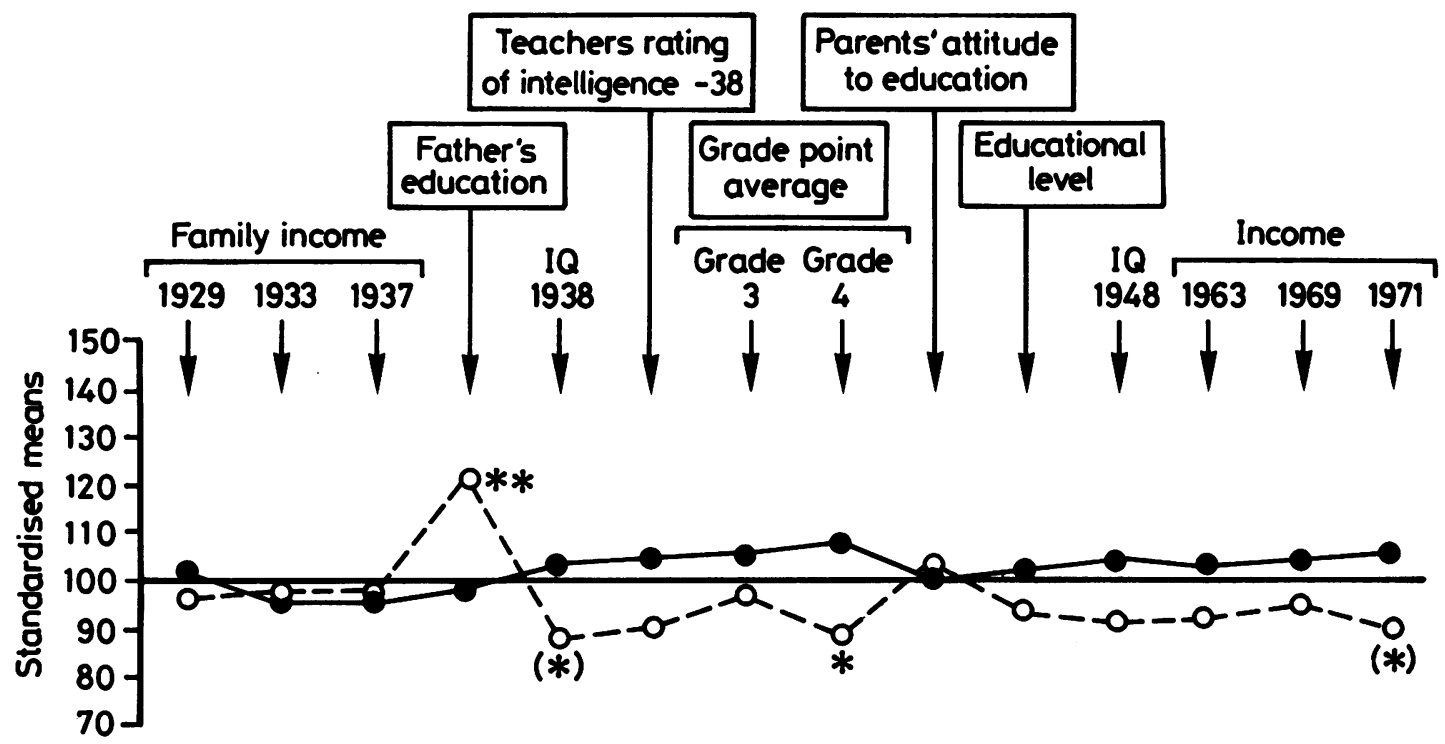

Fig 1 Standardised mean profiles for hypertensive (O) compared with "healthy" (O) men . 
the "healthy" men only by being to a greater extent single. Sixteen percent of this group were unmarried in 1971 compared to $10 \%$ of the "healthy" group $(p<0.05)$. The corresponding percentages at the time of the health investigation (1976-78) were $14 \%$ and $9 \%$ respectively $(\mathrm{p}<0.05)$. The proportion of divorced men increased during the same period in the hypertensive group from $11 \%$ to $14 \%$ and in the "healthy" group from $4 \%$ to $5 \%$.

Very few subjects were found in general criminal and social welfare records and give no valid information regarding group differences.

HEALTH STATUS AND LIFE STYLES AT THE AGE OF 48 As a consequence of the selection criteria used for identification of the "healthy" group, the hypertensive subjects differed in many respects. However, some variables that seem to be relevant are reported.

Bodyweight, blood pressure, and pulmonary function Figure 3 shows profiles of standardised means for the hypertensive compared with the "healthy" group. Differences between means were tested using $t$ tests. The hypertensive subjects were not only more obese than the "healthy" group, but their respiratory function was also inferior-peak flow (PF) and vital capacity (FVC) were significantly lower. The $p$ values are given in the figure.

\section{Body weight increase}

The hypertensive men had also to a larger extent $(58 \%$ against $25 \%)$ gained weight by more than $10 \mathrm{~kg}$ since age $30(p<0.01)$.
Physical activity at work and in free time

Physical activity at work and in free time has been mapped using 11 questions. The only difference between the hypertensive and "healthy" group concerns sedentary pastimes during free time. Nearly three-quarters of the hypertensive group stated that they mostly watch TV, go to the cinema, etc, during leisure time, compared with just under half of the "healthy" group $(\mathrm{p}<0.01)$.

Diabetes, cancer, and cardiovascular disease in the family

There were no differences between the two groups regarding diabetes or cancer in the family.

The hypertensive group differed from the "healthy" in the percentage who had a brother with high blood pressure. High blood pressure did not occur in a brother in any of the "healthy" individuals but did occur in $18.4 \%$ of the hypertensives $(p<0.001)$. In this connection it must, however, be noted, that there are more siblings in the hypertensive group than in the "healthy" group. The proportions are $89.5 \%$ and $69.7 \%$ respectively $(\mathrm{p}<0.05)$. The proportion of the hypertensive group whose mothers suffered cerebral haemorrhage or thrombosis was also larger than in the "healthy" group-21.1\% compared with $7 \cdot 7 \%$ $(p<0.05)$.

\section{Smoking and alcohol habits}

There were no differences between the two groups regarding actual smoking habits. The individuals' alcohol habits were studied using nine questions which were a Malmö modification of the Michigan

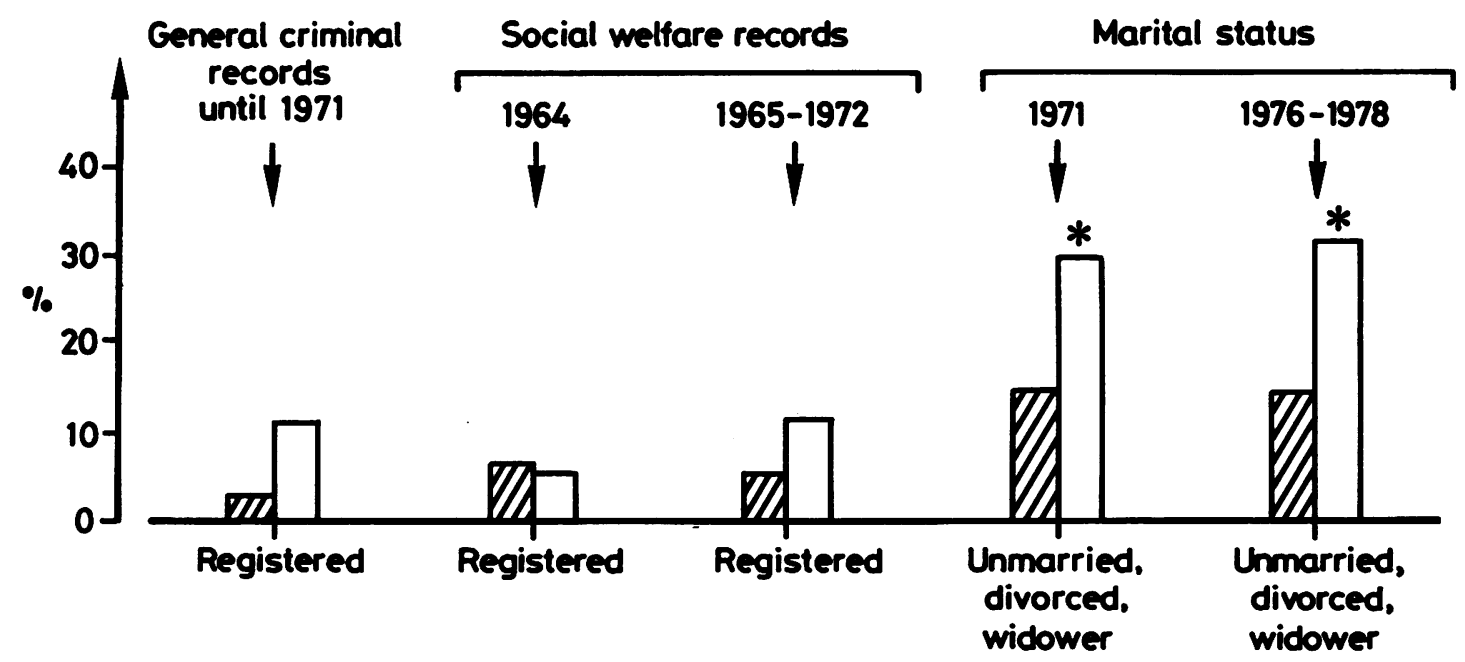

Fig 2 Social conditions in adulthood. Hypertensive $\square$ compared with "healthy" group. 
Parameters

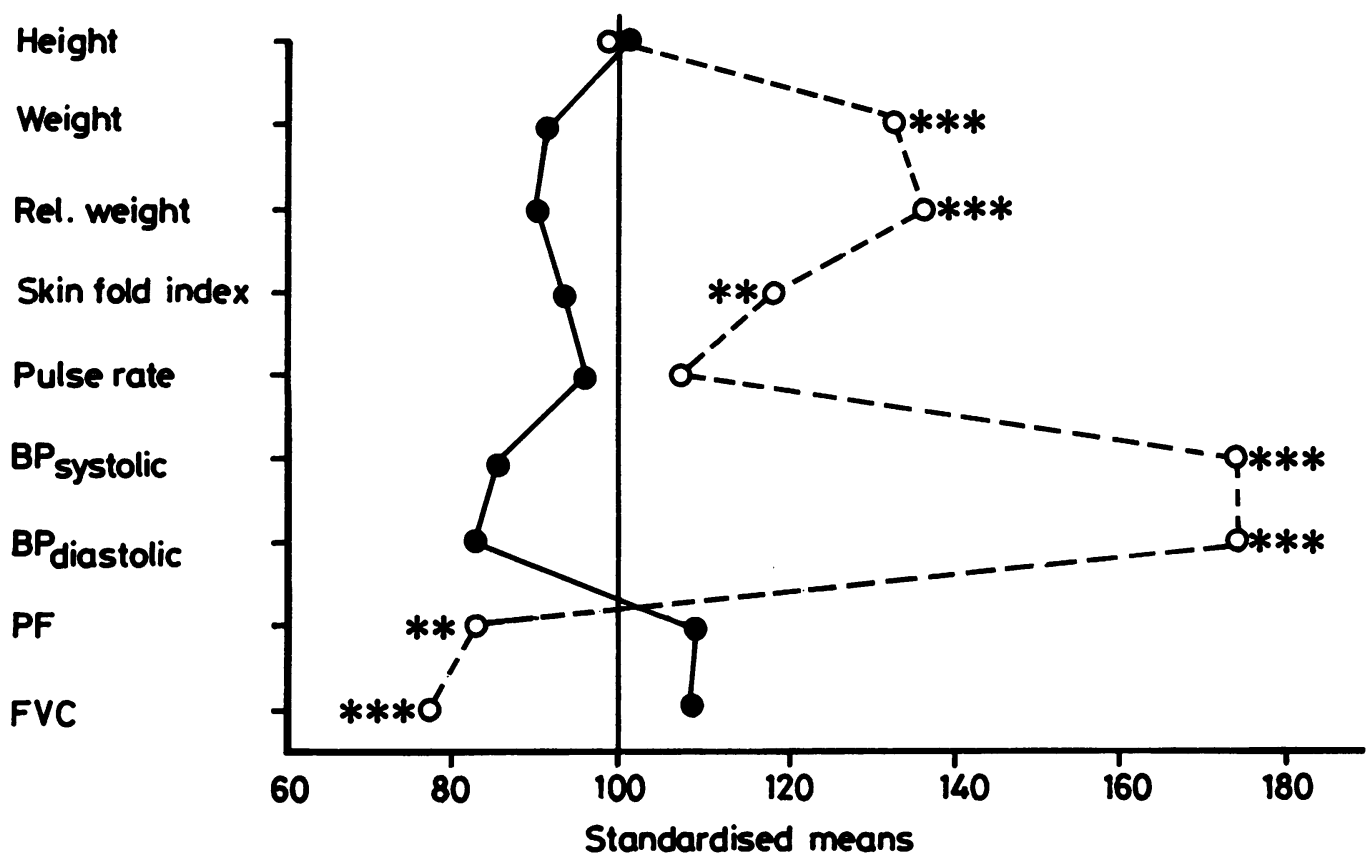

Fig 3 Biomedical parameters. Mean profiles for hypertensive (O) compared with "healthy" (O) men.

Alcoholism Screening Test-MAST. ${ }^{13}$ The Malmö modification, Mm-MAST, has been evaluated and described by Kristenson. ${ }^{14}$

The hypertensive group differed from the "healthy" in only one of the questions: just one-fifth of the hypertensive group said that they had a couple of drinks or beers a day to relax. This is a larger proportion than among the "healthy" $(p<0.001)$.

\section{Psychosocial conditions}

The individuals' psychosocial conditions were rated through questions representing the following five factors: stress, sleeping problems, impatience, family problems, and psychosocial working environment.

A significantly larger proportion of the hypertensive than of the "healthy" group: had experienced continual stress during the past five years $(p<0.001)$, had had sleeping problems $(p<0.001)$, had become impatient in stationary queues $(p<0.001)$, and felt that their work was uncongenial $(p<0.05)$.

\section{Discussion}

In a comparison between 48 year old men with essential hypertension and men of the same age without proven somatic or mental diseases at a health examination, we found that men with hypertension appeared to have, on average, an unfavourable income development. Another finding which also indicates that this group is psychosocially disadvantaged, was that many more men with hypertension were divorced, and that a larger number of the men had never been married, compared to the so-called healthy group.

Furthermore, subjects with hypertension had had more experiences of job dissatisfaction and continual stress during the last five years. These findings are in agreement with other cross-sectional studies reporting a connection between sustained blood pressure and conditions connected with psychosocial disadvantages. ${ }^{1516}$

Regarding lifestyles, men with hypertension in this study were more prone to use alcoholic beverages daily in order to relax, and reported lower physical activity during leisure time. As was expected, the hypertensive men were obese and had gained weight to a larger extent after the age of 30 than had the nonhypertensive controls.

As these relations cannot be interpreted in terms of cause and effect, the first aim of this study was to elucidate if these socioeconomic differences had been present already in the subject's childhood. If this was 
the case, the blood pressure differences might to a certain degree be explained by social class effect. ${ }^{7}$

In order to analyse the early influences of family social background, we had the opportunity to use a unique Swedish longitudinal study: The Malmö Study. ${ }^{8}$

No differences in socioeconomic conditions could be observed between the two groups during childhood years. We studied the families' incomes between 1929 and 1937 , and the families' "social welfare assistance, family composition expressed in family size and if only one adult was at home during this period." The only difference that could be shown was that fathers in the hypertensive group had had a longer education compared with the control group fathers. This should rather have been a positive factor for the children who later developed hypertension. Thus we cannot draw the conclusion that low socioeconomic status in childhood is "inherited" and this explains the observed difference between the group with hypertension and the so-called healthy men. Therefore it is not reasonable to conclude that the development of hypertension in adults can be explained by negative factors caused by having belonged to a lower social class during the first ten years of life.

It is natural to investigate if there are differences that can be attributed to personality or to the individual's way of reacting to stimuli in the environment. We found that the children who belonged to the group which later developed hypertension had a lower cognitive ability at the age of 10 , as measured by an intelligence test, their school achievement, and teacher evaluations. It is of special interest to note that there is a very strong difference between father's education and the son's cognitive ability in the group with hypertension. It is easy to surmise that this difference could be felt as a considerable stress factor. This hypothesis is supported by the fact that there is a positive attitude in the family concerning higher education which the children in the group with hypertension do not seem to be able to live up to as adults, considering their level of education and income development (fig 1). The lower income level that has been observed for the group with hypertension can probably be explained partly by a lower cognitive ability, which also is supported by the fact that in the total group $(n=379)$ there is a positive correlation between IQ 1938 and income 1971: $r=0.42$ $(\mathrm{p}<0.001)$.

No differences are found between the two groups concerning notations in the criminal or social registries when the persons have become adults. However, since only a small number of persons are registered there, one can hardly expect to find significant differences.

We have reported formerly that early mortality (before 50 years of age) in this investigated group has a correlation of a low IQ and poor socioeconomic conditions in childhood. ${ }^{12}$

The observation that is now reported, that a lower cognitive ability between the two groups seems to be related to both the development of blood pressure and to other variables which are risk factors concerning cardiovascular illness such as obesity, ${ }^{17}$ physical inactivity, ${ }^{18}$ lower education and income, ${ }^{19}$ and dislike of one's work, ${ }^{20}$ indicate that a lower mental capacity could be an indicator of weakness in general and a forerunner of vascular disease. There are several studies that show that coronary risk factors, including blood pressure and coronary heart disease, are connected with employment grade, ${ }^{21}$ social class, and education. ${ }^{22-24}$ The observation in our study that cognitive factors, as measured at an early age, can explain variations in education and thus choice of career and the person's social class would partly be able to explain the process that leads to differences in cardiovascular illnesses in the different social groups.

The next step in the continued analysis of the complex relations between psychosocial factors in childhood and medical risk variables, including hypertension at an adult age, demands a finer statistical analysis, where consideration is given to the long investigation time. This analysis should include all men in the investigation group.

We thank the Malmö Study longitudinal research group at the Institute of International Education, University of Stockholm, for many years of close and valuable collaboration.

The study has been supported by grants from the Swedish National Association against Heart and Chest Diseases, the National Association for Heart and Chest Patients, and the Swedish Delegation for Social Research, Ministry of Health and Social Affairs.

Correspondence to: Dr Folke Lindgärde, Department of Medicine, Malmö General Hospital, S-214 01 Malmö, Sweden.

\section{References}

${ }^{1}$ Modan M, Halkin H, Almog S, et al. Hyperinsulinemia. A link between hypertension, obesity and glucose intolerance, J Clin Invest 1985; 75: 809-17.

2 Blair SN, Goodyear NN, Gibbons LW, Cooper KH. Physical fitness and incidence of hypertension in healthy 
normotensive men and women. JAMA 1984; 252: 487-90.

3 Pinsky JL, Branch LG, Jette AM, Haynes SG, Feinleib M, Cornoni-Huntley JC, Bailey KR. Framingham disability study: Relationship of disability to cardiovascular risk factors among persons free of diagnosed cardiovascular disease. Am J Epidemiol 1985; 122: 644-56.

${ }^{4}$ Keil JE, Tyroler HA, Sandifer SH, Boyle E. Hypertension: Effect of social class and racial admixture. Am J Public Health 1977; 67: 634-9.

${ }^{5}$ Rose RM, Jenkins CD, Hurst MW. Air traffic controller health change study: A prospective investigation of physical, psychological, and work-related changes. Levin MA, ed: Boston University School of Medicine. Boston. 1978 (Reprinted by the Federal Aviation Adminstration, Washington, DC).

6 Jenkins CD, Hurst MW, Rose RM, et al. Biomedical and psychosocial predictors of hypertension in air traffic controllers. In Spielberger CD. Saraon IG, Defares PB (eds): Stress and anxiety. Vol. 9. New York: Mcgraw-Hill Hemisphere, 1981 .

${ }^{7}$ Antonovsky A. Social class, life expectancy and overall mortality. Milbank Mem Fund $Q$ 1967; 45: 31-73.

${ }^{8}$ Husén T, Emanuelsson I, Fägerlind I, Liljefors R. Talent opportunity and career. A twenty-six year follow-up of 1500 individuals. Stockholm: Almqvist et Wiksell, 1969.

${ }^{9}$ Fägerlind I. The Malmö Study. In SA Mednick, AE Baert (Eds) Prospective longitudinal research: An empirical basis for the primary prevention of psychosocial disorders. Published on behalf of the WHO Regional office for Europe. Oxford, New York, Toronto, Melbourne: Oxford University Press, 1981.

${ }^{10}$ Furu M. Life patterns and health. A longitudinal study of men from childhood to middle age. Stockholm Institute of Education, Department of Educational Research, Lund: Liber, Diss 1985.

11 Trell E. Community-based preventive medical department for individual risk factor assessment and intervention in an urban population. Prev Med 1983; 12: 397-402.

12 Furu M, Lindgärde F, Ljung BO, Munck I, Kristensson H. Premature death, cognitive ability and socioeconomic background. A longitudinal study of 834 men. Stockholm: Institute of Education, Department of Educational Research, 1984; Report No. 1.
${ }^{13}$ Selzer, ML. The Michigan alcoholism screening test: The quest for a new diagnostic instrument. Am J Psychiatry 1971; 127: 1653-8.

${ }^{14}$ Kristensson, H. Studies on alcohol related disabilities in a medical intervention programme in middle-aged males. Malmö: The Departments of Alcohol Diseases and Internal Medicine and Section of Preventive Medicine, University of Lund, Malmö General Hospital. Diss. 1982.

${ }^{15} \mathrm{Kasl}$ SV, Cobb S. Blood pressure changes in men undergoing job loss: A preliminary report. Psychosom Med 1970; 32: 19-38.

${ }^{16}$ Harburg E, Erfurt JC, Chape C, Hauenstein LS, Schull WJ, Schork MA. Socioecological stressor areas and black-white blood pressure-Detroit. J Chron Dis 1973; 26: 595-611.

${ }^{17}$ Borkan GA, Sparrow D, Wisniewski C, Vokonas PS. Body weight and coronary disease risk: Patterns of risk factor change associated with long-term weight change. Am J Epidemiol 1986; 124: 410-9.

${ }^{18}$ Morris JN, Chave SPW, Epstein L, Sheehan DJ. Vigorous exercise in leisure-time and the incidence of coronary heart disease. Lancet 1973; i: 333-9.

${ }^{19}$ Dyer AR, Stamler J, Shekelle RB, Schoenberger J. The relationship of education to blood pressure. Findings on 40000 employed Chicagoans. Circulation 1976; 54: 987-92.

${ }^{20}$ Karasek RA, Russell RS, Theorell T. Physiology of stress and regeneration in job related cardiovascular illness. $J$ Human Stress 1982; 8: 29-42.

${ }^{21}$ Marmot MG, Rose G, Shipley M, Hamilton PJS. Employment grade and coronary heart disease in British civil servants. J Epidemiol Community Health 1978; 32: 244-9.

${ }^{22}$ Marmot MG, Rose G, Shipley MJ. Inequalities in death - specific explanations of a general pattern? Lancet 1984; ii: 1003-6.

${ }^{23}$ Tuomilehto J, Puska P, Virtamo J, Neittaanmäki L, Koskela K. Coronary risk factors and socioeconomic status in eastern Finland. Prev Med 1978; 7(4): 539-49.

${ }^{24}$ Holme I, Helgeland A, Hjermann I, Lund-Larsen PG, Leren $\mathrm{P}$. Coronary risk factors and socio-economic status. The Oslo Study. Lancet 1976; ii: 1396-8. 